pressure, was found to fluctuate slightly, and also to catch water which sometimes was forced back from the aspirator.

Under these conditions water in $B$ can be made to boil under a pressure of from 20 to $30 \mathrm{~cm}$. As soon as pressure and temperature have become constant, both are recorded. The stopcock $S$ is then partly closed so that steam is generated in the boiler faster than it escapes and the pressure thereby increased. By regulating the stop-cock the pressure can be kept constant at any point desired and readings of temperature made for every four or five centimeters increase in pressure. After the pressure becomes equal to that of the atmosphere the tube is disconnected from the aspirator and the pressure carried up as high as the strength of the boiler and the graduations on the thermometer will safely allow.

A range of pressure from about $26 \mathrm{~cm}$. to $115 \mathrm{~cm}$., corresponding to a range of temperature from about $70^{\circ}$ to $110^{\circ}$ was easily and safely attainable by the student and the data when platted gave a very good curve, bringing out the relationship between the vaporization and temperature of a liquid in an excellent man, ner.

\title{
A SKELETON TELESCOPE.
}

BY E. C. WOODRUFF.

\section{Instructor of Physics, LaGrange (IIl.) High School.}

"Is that all there is to a telescope?" This question was asked by a pupil of average brightness when he first saw the apparatus here to be described.' The work in class on the text in light had evidently only increased the mystery of the telescope to him. The question constitutes half the argument for the writing of this article. The importance of the experiments on images in telescopes and microscopes (No. 131 in Nichol, Smith and Turton's "Manual" and No. 82 in Ayres' "Manual") is emphasized by the same argument. The apparatus is intended to furnish a definite instrument for these experiments so as to avoid the use of pick-up pieces from the outfits of other experiments. It is also intended to be used in mirror and scale work (vid. Schoor Science, Vol. II., p. 94, 
April, 1902), where conventional reading telescopes are beyond the reach of the school. The design was originally in response to a definite request for such a device.

The construction is as follows (Fig. 1): $O$ is an ordinary plano-convex lens of about $20 \mathrm{~cm}$. focal length. $E$ is such a doubleconvex lens as jewelers use-mounted, perhaps, in a flaring rubber tube $T$, and of about $6 \mathrm{~cm}$. focal length. Used as a telescope the combination will have a magnifying power of about 3 diameters. $B$ is a base board, $28 \times 5 \times 2 \mathrm{~cm}$. $L$ is an upright, $5 \times 5 \times 2 \mathrm{~cm}$., screwed to $B$ and carrying the eye-piece $E$. $S$ is a similar upright carrying the object-lens $O$, but fastened to the side-bars $b$, one on either side of $B$, and so free to slide along the base. $C$ is a cross-bar resting on top of $B$ and holding the two bars $b$ together. $W$ is a wire, one end fastened to $B$, pointed at the other end, and bent at right angles

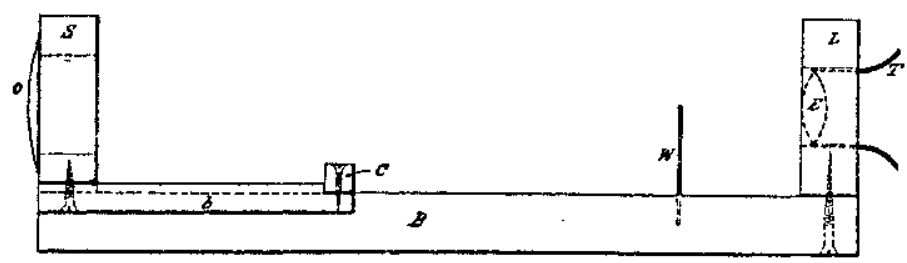

Fig. 1.

so as to bring the point horizontally into the center of the field of $E$ to serve as a cross-wire.

Turn the instrument end for end and you have a compound microscope. The experiments are performed just exactly as directed in the Manuals.

Of course, when used as a reading telescope the definition is very good only in the eenter of the field, but that is all that is necessary. A dark cloth thrown over the instrument makes reading a little easier.

The simplicity of the arrangement appeals to the pupil. Many pupils will no doubt construct such instruments for themselves from reading glasses and hand magnifiers found lying around in most every house, thereby deriving considerable benefit. 